\title{
Supporting evidence-use in networked professional learning: The role of the middle leader
}

\author{
Danielle LaPointe-McEwan, Christopher DeLuca, \& Don A. Klinger \\ Faculty of Education, Queen's University, Kingston, Canada
}

Full Citation:

Danielle LaPointe-McEwan, Christopher DeLuca \& Don A. Klinger (2017) Supporting evidence use in networked professional learning: the role of the middle leader, Educational Research, 59:2, 136-153, DOI: 10.1080/00131881.2017.1304346

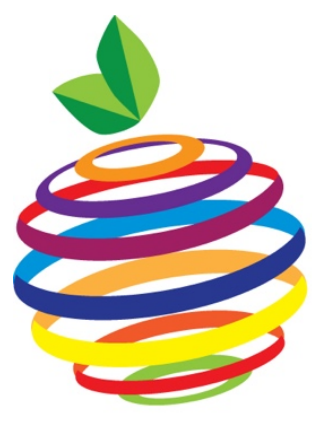

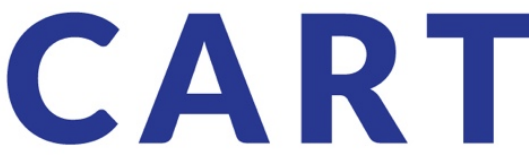

Classroom Assessment Research Team cdeluca.com

\author{
Contact: \\ Christopher DeLuca \\ cdeluca@queensu.ca \\ @ChrisDeLuca20
}




\begin{abstract}
Background: In Canada, contemporary collaborative professional learning models for educators utilise multiple forms of evidence to inform practice. Commonly, two forms of evidence are prioritised: (a) research-based evidence, and (b) classroom-based evidence of student learning. In Ontario, the integration of these two forms of evidence within professional learning is increasingly facilitated by 'middle leaders' - school district level educators who support system change through sustained school- and classroom-embedded professional development with teachers.
\end{abstract}

Purpose: This study investigated the role of the middle leader in supporting teachers' use of research- and classroom-based evidence within the context of collaborative professional learning. It was guided by the following research questions: (a) What is the capacity of middle leaders to use research- and classroom-based evidence within professional learning contexts? (b) What challenges do middle leaders encounter in using research- and classroom-based evidence within professional learning contexts? and (c) How do middle leaders develop their capacity for evidence-use within professional learning contexts?

Program Description: The context for this study was a three-year networked professional learning project that included nine school districts in Ontario, Canada. An evidence-based collaborative inquiry approach was used to explore the common goal of improving mathematics teaching and learning across the nine districts.

Participants: A purposeful sample of 30 middle leaders (i.e., system facilitators) and 54 teachers (36 Primary/Junior school teachers [student ages $4-11$ ] and 18 Intermediate/Senior school teachers [student ages $12-18$ ]) across the nine school districts was selected based on these educators' high degree of engagement in the project and willingness to participate in data 
collection. System facilitators were relative experts in mathematics instruction and provided differentiated and embedded support in mathematics pedagogy to school inquiry teams (i.e., school administrators and selected teachers), responsive to their local needs and goals.

Design and Methods: A qualitative approach was used, comprising focus groups conducted at the end of each project year with study participants. Data collection yielded 27 system facilitator focus groups (nine per year) and 27 teacher focus groups (also nine per year), each transcribed verbatim.

Findings: Standard thematic coding of focus group data was used to elucidate four emergent themes across system facilitators and teachers: (a) realising the need for data literacy in the construction of classroom evidence, (b) challenges to evidence-use, (c) support enabling evidence-use, and (d) changing attitudes about evidence. Overall, findings indicated that both middle leaders and teachers required data literacy to use, successfully, classroom evidence within a collaborative inquiry. Although middle leaders encountered challenges to facilitating teachers' classroom evidence-use in collaborative inquiry, they developed their own data literacy through regular cross-district middle leader learning sessions and targeted support from pedagogical and research experts. While both middle leaders and teachers shifted their attitudes and practices with respect to classroom evidence-use within the project, this finding did not extend to their critical interrogation of research evidence sources (i.e., research literacy).

Conclusions: Middle leaders play a central role in promoting evidence-use within networked collaborative professional learning. Diverse strategies are needed to support middle leaders' use of both research- and classroom-based evidence throughout collaborative inquiry cycles, to inform and monitor classroom, school, district, and regional impacts. While increased data 
literacy may enhance educators' use of classroom evidence, it may not directly impact their uptake of research to inform their collaborative inquiries.

\section{Keywords}

Teacher professional learning, networked professional learning, middle leaders, evidence-use 


\section{Introduction}

This article presents findings from a study investigating the role of middle leaders in Canada in supporting teachers' use of research- and classroom-based evidence, within the context of collaborative professional learning in mathematics. The study involved teachers from Primary/Junior schools and Intermediate/Senior school backgrounds.

Each year, educational systems in many nations allocate extensive resources to support evidencebased professional learning among educators, to improve instructional practices and student achievement (Desimone 2009; Fullan 2007, 2009; Hattie 2013). In Canada, there is a trend towards professional learning models that prioritise educators' use of evidence within sustained and collaborative professional inquiries that are focused on discrete problems of practice. Typically, these collaborative inquiries involve recursive cycles of co-learning that integrate multiple forms of evidence, yet prioritise: (a) evidence from educational research, and (b) classroom-based evidence on instructional effectiveness (i.e., student assessment data) (Campbell and Levin 2009; Donohoo 2013; Leithwood, Aitken, and Jantzi 2006). These two forms of evidence require educators (a) to interpret and (b) to construct a variety of sources to inform their inquiry. Research has shown that educators face challenges with this evidence-based approach to professional learning, as many have limited evidence-literacy: that is, research or data literacy skills (i.e., the knowledge and skills to collect, analyse, and use evidence) (Campbell and Levin 2009; Cochran-Smith and Lytle 2009; DeLuca, Shulha, Luhanga, Shulha, Klinger, and Christou 2015). Within collaborative inquiry, this limited evidence literacy not only impedes educators' ability to construct and use classroom-based evidence (data literacy) but also their ability to interrogate evidence from educational research (research literacy). In this paper, 
we clearly differentiate educational research evidence from classroom-based evidence: the former relates to academic studies and publications; the latter involves the use of classroom data (i.e., assessments and other classroom artifacts) that provide information about instructional effectiveness.

In the Canadian province of Ontario, leveraging the role of middle leaders - school district level educators who facilitate system change - has emerged as a strategy to support teachers' inservice collaborative inquiry and evidence-use (Fullan 2015). Fullan describes leadership from the middle as "a deliberate strategy that increases the capacity and internal coherence of the middle as it becomes a more effective partner upward to the state and downward to its schools and communities, in pursuit of greater system performance" (23). While the middle leadership strategy is implemented differently across contexts and countries, findings from two recent professional learning initiatives in Canada and the United Kingdom suggest that the middle leader approach has the capacity to enable: (a) learning responsive to diverse local needs and goals, (b) cross-district or cross-regional ownership for students' learning and each other's success, (c) alignment among local, systemic, and regional priorities, and (d) evidence-informed professional learning and practice across districts or regions (Hargreaves and Ainscow 2015). Similarly, a New Zealand initiative further elucidated the importance of leveraging the role of middle leaders, also known as facilitators, in conjunction with external experts, to cultivate trusting professional relationships among educators to support enhanced instructional practices and student outcomes (Fullan 2015). 
Despite the anticipated benefits of the middle leader in facilitating teacher development, there is little empirical research focused directly on the role of the middle leader in supporting evidenceuse and uptake. Specifically, studies are required that examine the capacity of middle leaders to enable teachers effectively to use evidence from both educational research and classroom-based assessments to guide professional learning (Fullan 2015; Hattie 2013). Therefore, the purpose of this study is to focus specifically on the role of middle leaders in Ontario, Canada, as they work to support teachers' use of research- and classroom-based evidence within collaborative inquirybased professional learning contexts. Guiding this study are the following research questions:

1. What is the capacity of middle leaders to use research- and classroom-based evidence within professional learning contexts?

2. What challenges do middle leaders encounter in using research- and classroom-based evidence within professional learning contexts?

3. How do middle leaders develop their capacity for evidence-use within professional learning contexts?

\section{The Role of Middle Leaders}

Across nations, educational systems are commonly conceptualised as comprised of three levels: top (state or province), middle (region or district), and bottom (schools) (Fullan 2015). In Ontario, leaders in the middle level are often former classroom teachers operating in intermediary support roles as system facilitators. System facilitators work across multiple levels of school districts - supporting the evidence-based professional learning of individual teachers in classrooms and groups of educators in schools in order to achieve system goals and priorities (Hargreaves and Ainscow 2015; Killion 2012; Muijs, West, and Ainscow 2010). Moreover, 
system facilitators are often responsible for demonstrating the impact of educator professional learning programs across classrooms and schools to district administrators, governments, or funding agencies (Avalos 2011; Fullan and Knight 2011). In this way, system facilitators must support systemic evidence collection through ongoing assessment for learning strategies, "balancing the use of data for external accountability with the purposeful and professional use of data for internal accountability and improvement processes" (Campbell and Levin,2009, 62).

Facilitators are generally selected based on previously demonstrated excellence as classroom teachers and relative expertise in a specific teaching domain (Fullan 2015; Killion 2012). Within collaborative inquiry professional learning models, facilitators engage groups of educators (i.e., teachers, school leaders, and external experts) in recursive cycles of learning to explore problems of practice based on classroom evidence of students' learning (DeLuca et al. 2015; Ermeling 2010; Nelson and Slavit 2007). In most cases, facilitators provide ongoing and job-embedded learning opportunities grounded in educational research evidence, modelling new approaches to instruction and assessment (Avalos 2011; Nelson and Slavit 2007; Timperley 2011).

Effective facilitation of collaborative inquiry requires (a) knowledge of relevant professional learning content and related research evidence, (b) skills in facilitation practices (i.e., implementing various pedagogical approaches with adult learners), and (c) data literacy (i.e., use of multiple sources of evidence to inform and monitor professional learning). In most cases, facilitators receive targeted support in specific content areas and in facilitation strategies; however, facilitators less consistently receive support in developing their evidence literacy skills (Avalos 2011; Kennedy, Deuel, Nelson, and Slavit 2011; Schildkamp, Poortman, and 
Handelzalts 2016; Timperley 2011). This lack of support is problematic, as facilitators' abilities to use classroom and external evidence to inform and monitor teacher learning remains central to effective educator learning (Fullan and Knight 2011; Wellman and Lipton 2004). Moreover, in collaborative inquires facilitated by teachers fulfilling system-level support roles, these facilitators must concurrently develop their own evidence literacy while also supporting the evidence literacy of educators in their collaborative inquiry groups. Accordingly, the notion of middle leaders operating as system facilitators plays a central role in contemporary evidencebased professional learning models.

\section{Evidence-based Professional Learning}

Over the past 20 years, there has been a paradigm shift in approaches to educator professional learning, in response to the international concern that traditional models often failed to achieve desired and sustained outcomes for educators and students (Borko,2004; Darling-Hammond and Richardson 2009; Guskey 2014). Traditional professional learning was characterised through expert instruction that was often detached from classroom contexts and focused on isolated practices (Borko 2004; Opfer and Pedder 2011; Timperley 2011). Newer notions of educator professional learning have moved toward job-embedded models in which educators in various roles collaborate on core problems of practice through evidence-based inquiry (Cochran-Smith and Lytle 2009; Donohoo 2013; Hattie 2013; Leithwood et al. 2006). Researchers have increasingly acknowledged the complexities associated with such contemporary educator learning initiatives - characterising these efforts as the simultaneous activities of individual teachers, schools, and collectives engaged in learning within and across levels of educational systems (Campbell and Levin 2009; Mooleanr 2012; Opfer and Pedder 2011). As a result, 
conceptions of educator professional learning have moved away from a linear 'cause and effect' orientation to recognise that contemporary professional learning models must simultaneously meet micro (individual and school), meso (district and region), and macro (systemic and national) needs (Bore and Wright 2009; Campbell and Levin 2009; Davis and Sumara 2006; Muijs et al. 2010).

Some common characteristics of effective educator learning models have been identified across the professional learning literature. In particular, there is relative agreement that effective professional development supports educators' learning through instructive, reflective, active, collaborative, and substantive learning opportunities (Borko 2004; Darling-Hammond 2010; Desimone 2009; Donohoo 2013; Elmore 2004; Guskey and Yoon 2009; Nelson and Slavit 2008; Quatroche, Bauserman, and Nellis 2014). Within these models, educators are asked to use educational research evidence to understand and respond to local problems of practice. While it is widely accepted that leveraging research evidence to inform professional learning contributes to deeper learning, more effective practices, and improved outcomes for educators and students (Darling-Hammond and Richardson 2009; Desimone 2009; Hattie 2013), there are some studies demonstrating that educators' integration of research evidence is limited, pointing to low levels of research literacy among educators (Cooper, Levin, and Campbell 2009; Nelson and Slavit 2008; Timperley 2011). These studies further emphasise that the integration of research into educator learning requires intentionality and support. Within professional learning initiatives, designated individuals and organisational structures are necessary to help educators find, share, and use research evidence purposefully to enhance intended outcomes ( $\operatorname{Sin} 2008$ ). 
Moreover, educators engaged in professional learning are increasingly called to collect, analyse, and use classroom evidence on the effectiveness of their changing instructional practices. In particular, educators' collaborative inquiries are predicated on their use and analysis of student assessment data to inform their subsequent learning and practice. Campbell and Levin (2009) argue that systemic changes through professional learning need to be supported through a balancing of evidence from diverse classroom assessments and external measures. They further emphasise that effective professional learning systems commit to implementing assessment for learning strategies at classroom, school, and district levels in order to create learning cultures that value evidence as an ongoing incitement for professional development. However, as articulated by Fullan (2007), this commitment requires educators to have the data or assessment literacy necessary to collect, systematically, their own classroom evidence related to the effects of their professional learning on student outcomes. Furthermore, educators must blend this classroom evidence with external accountability measures. Consequently, the need to support educators' development of data literacy has been identified as an essential component of contemporary professional development models (DeLuca et al. 2015; Earl and Katz 2006; Hattie 2013; Timperley 2011), and appears to be a critical issue in order to fulfill the intentions of evidencebased collaborative professional learning (Huffman and Kalnin 2003; Kennedy et al. 2011; Robinson 2010; Vineyard 2010; Wellman and Lipton 2004). Despite the importance of data literacy in current professional learning models, previous studies have shown that educators generally maintain relatively low data literacy levels (Campbell and Levin 2009; Cochran-Smith and Lytle 2009; DeLuca et al. 2015; Schildkamp et al. 2016). Accordingly, there have been calls for additional research on effective strategies to support educators' data literacy in order to enhance their use of classroom and research evidence within collaborative inquiry approaches to 
professional learning.

\section{Context for the study}

This study was conducted across nine Ontario school districts that engaged in a three-year professional learning project within an established regional network. The network was formed twenty-five years ago to complement the work of school districts in the region, by organising and delivering professional learning opportunities in response to identified regional needs. The nine school districts in the network are small or medium in size (each serving from 4,700 to 72,565 students), represent a largely rural geography, and serve approximately ten percent of the student population in the province.

The three-year professional learning project facilitated ongoing learning opportunities for approximately 1100 teachers across the region, through a middle leader strategy. The project was supported and monitored by a regional team of 43 system facilitators, representing each of the nine school districts involved. The common regional collaborative inquiry across these districts focused on improving mathematics teaching and learning through the big idea of proportional reasoning. Within the common project focus, educators in participating districts, schools, and classrooms were given the latitude to identify collaborative inquiries that reflected local needs and interests (see Figure 1). All collaborative inquires within the project were rooted in educational research evidence of effective pedagogy, assessment practices, and approaches to facilitation in mathematics. 
At the regional level the 43 system facilitators comprised of district teams of three to five facilitators, engaged in monthly cross-district learning sessions focused on strategic implementation and monitoring of the initiative. These monthly learning sessions were facilitated by two project leads and two university research partners associated with the project, with targeted support from knowledge experts and Ontario Ministry of Education staff. System facilitators were given the flexibility to adapt materials and concepts to their own district's specific learning needs and goals, provided that each district's focus was related to the overarching goal of the project. Therefore, each system facilitator team operationalised their collaborative inquiry differently, based on district-specific priorities and local needs in schools. Professional learning activities for teachers in the project occurred at regional, school district, and school levels and were supported by knowledge experts, Ministry of Education staff, and system facilitators. Regional and school district sessions were typically led by knowledge experts and focused on general learning about foundational concepts and pedagogical strategies in mathematics. School-based sessions engaged inquiry teams, which were comprised of school administrators and selected teachers who met regularly with their system facilitators to further build capacity in foundational concepts and explore implementation of new mathematics pedagogy. Facilitators provided differentiated and embedded support to school inquiry teams, responsive to their local needs and goals. In most cases, facilitators: (a) leveraged educational research evidence to support professional learning and dialogue among inquiry teams; (b) modelled and supported implementation of new instructional strategies in classrooms; and (c) helped teachers collect and analyse classroom data to inform next steps in professional learning and practice (i.e., assessment for learning). 


\section{Methods}

The study adopted a qualitative approach. It included focus group interviews conducted at the end of each year of the project, with a purposeful sample of 30 system facilitators and 54 teachers. These participants were selected based on their high degree of engagement in the project and willingness to participate in data collection. We acknowledge that the inclusion of already-motivated project participants is one of a number of factors that may limit the transferability of findings.

We recruited system facilitator participants, with whom we worked to recruit teacher participants. Teacher focus group data were included to enhance the trustworthiness of findings pertaining to facilitators. Ethical consent for all data collection was obtained through each participating school district. Study participants were assured of the anonymity of focus group comments and that their names and personal information would not be published. The reporting of study findings in this paper fully upholds all assurances of anonymity that were afforded to participants. Following Katz and Earl's (2010) approach, all interview protocols were grounded in the professional learning project theory and centred on how facilitators and teachers developed their capacity for evidence-use throughout the project.

All 43 system facilitators involved in the project were invited to participate in focus groups. The achieved sample (30) represented over two thirds of facilitators. On average, this sample of 30 included three to five facilitators per district across the nine districts. They had varying levels of experience in their roles, but all were experienced in terms of collaborative inquiry in 
mathematics. Over half of these facilitators had been involved in the regional project for all three years, and most had completed Additional Qualifications courses or were specialists in mathematics (see Table 1). System facilitators each invited up to ten teachers per district to participate in focus groups. The achieved sample of 54 teachers represented around one twentieth of the teachers involved in the project. On average, there were four to eight per district across the nine districts. Thirty-six teachers in the sample represented the Primary/Junior division (Kindergarten-Grade 6; approximate student ages 4 - 11), with 18 Intermediate/Senior teachers (Grades 7-12; approximate student ages 12 - 18) completing the sample. All teachers were experienced or expert in their teaching careers, and most were experienced with collaborative inquiry in mathematics. A majority of teachers had been involved in the regional project for two or three years, and some had completed Additional Qualifications courses or were specialists in mathematics (see Table 1).

\section{[Insert Table 1 Here]}

Facilitator focus groups were conducted at the end of each year of the three-year project. One focus group of three to five facilitators was conducted in each of the nine districts each year. This yielded a total of 27 facilitator focus groups over the three-year period. Sample interview questions included: (a) How has your involvement in this project impacted your use of research and classroom evidence to inform collaborative inquiry in mathematics? (b) What professional learning experiences in the project have supported your capacity to use research and classroom evidence to inform learning and practice? (c) How has your own capacity to use research and classroom evidence supported the evidence-use of teachers you work with in the project? and (d) 
Thinking about this initiative, what are some of the challenges you faced constructing, interpreting, and using classroom evidence to inform learning and practice in your district? Interviews, which were recorded, lasted approximately one hour each.

Teacher focus groups were conducted with teachers from each of the nine school districts (four to eight per focus group) at the end of each year of the three-year project. This yielded a total of nine teacher focus groups per year and 27 teacher focus groups over three years. Sample interview questions included: (a) How has your involvement in this project impacted your use of research and classroom evidence to inform collaborative inquiry in mathematics? (b) What professional learning experiences in the project have supported your capacity to use research and classroom evidence to inform learning and practice? (c) How has your own capacity to use research and classroom evidence supported teaching and learning in your mathematics classroom? and (d) Thinking about this initiative, what are some of the challenges you faced constructing, interpreting, and using classroom evidence to inform learning and practice in your classroom or school? The focus groups were recorded. Each lasted approximately one hour.

The recordings of the facilitator and teacher focus groups were transcribed verbatim, yielding 54 transcripts (i.e., 27 facilitator and 27 teacher transcripts). All were analysed using a standard inductive thematic coding process (Namey, Guest, Thairu, and Johnson 2008; Patton 2002). From an initial analysis of the data, a code list was generated. A team of three researchers used the code list to code all qualitative data independently, with an inter-rater agreement of $97 \%$. Where there was disagreement, the data was discussed and re-coded. Codes with a high degree 
of co-occurrence (i.e., two or more codes) were collapsed into broader themes that encompassed data from both facilitators and teachers.

\section{Study findings}

Data from facilitators and teachers were combined to generate emergent themes. Representative quotations are presented from both participant groups. Four themes emerged in relation to facilitators' capacity to support evidence-based collaborative professional learning among teachers: (a) realising the need for data literacy in the construction of classroom evidence, (b) challenges to evidence-use, (c) supports enabling evidence-use, and (d) changing attitudes about evidence.

\section{Realising the need for data literacy in the construction of classroom evidence}

This first theme relates to facilitators' initial realisation about the significant need for data literacy among educators within a collaborative inquiry approach to professional learning. Notably, this realisation was specific to the construction of classroom evidence and did not extend to educators' capacity to interrogate research evidence utilised within their collaborative inquiries.

Facilitators described how the regional collaborative inquiry model was an "evidence-based approach to professional development" in which "teachers need to analyse and use student assessments and other sources of classroom evidence to engage in collaborative learning." During the first year of the project, all facilitators realised that teachers' ability to construct and use classroom evidence was hindered by their limited data literacy. One facilitator specifically 
noted, “At the start of the project, teachers weren't sure what student-level data to collect in their math classrooms. When we met for our scheduled collaborative inquiry sessions, they either brought too much or nothing at all. This made it hard for us to collectively use the data to determine our next steps in learning and practice.”

Linked to teacher need for data literacy, facilitators recognised that they also required this foundational skill set in order to effectively support teachers' use of classroom data. One facilitator stated, "I realised that I had a lot to learn about how to use data from the math classroom - what to collect, how to analyse it, what counts as good evidence." Another elaborated, "We are so used to collecting and analysing student products in math. Through the project, I recognised that I needed to learn how to help teachers collect observations and conversations as well, so they can build more trustworthy evidence of change in their students' learning." It became increasingly evident during the first year that teacher data literacy was directly related to facilitator data skills. Specifically, facilitators required enhanced data literacy in order to effectively support teachers' use of classroom data within collaborative inquiry.

Throughout the second and third years of the project, facilitators intentionally developed and refined their data literacy through various professional learning experiences, including regional and district-embedded sessions with research experts. By the end of year three, all facilitators described significant growth in their capacity to leverage classroom evidence to support teacher learning. One facilitator noted, "Now we can help teachers in using pedagogical documentation, assessment for learning techniques, and diagnostic assessments to track and facilitate their learning." Another facilitator stated, "Our inquiries are much more specific and targeted for each 
school now. We plan, act, observe, and reflect in three-month short cycles of inquiry, supported by data. Teacher plans are beginning to change, and student work is changing."

At first, facilitators' realisation of the need for their own data literacy related specifically to their capacity to support teachers' use of classroom evidence within school-based collaborative inquires. However, as the project progressed, facilitators became increasing aware of their need to demonstrate district-level evidence of professional learning. At the end of the first year, facilitators primarily collected fixed-response teacher surveys as evidence of district-level project impact on mathematics teaching and learning; whereas, by the end of year three, facilitators had collected multiple sources of largely qualitative data (such as observations, interviews, annotated student work samples, photographs, and videos) over time to demonstrate project impact across the district. At the end of the project, one facilitator summarised the learning in this way: "The project has helped us create a strong inquiry question and data collection plan for our Board. As a result, we felt much more focused in the work we were doing with our teachers, and about the data we were collecting as evidence to support our Board inquiry."

\section{Challenges to evidence-use}

The second theme related to three challenges that middle leaders experienced using evidence across the networked professional learning context: (a) supporting various collaborative inquires at the same time, (b) recognising the complexity of data and evidence-use, and (c) tensions between local data priorities and methods and provincial expectations. 
First, a majority of facilitators felt challenged to support and monitor systematically the various concurrent collaborative inquiries occurring throughout schools in their districts. One facilitator explained, "Each of our school inquiry teams is exploring unique but interrelated areas of practice. How do we integrate evidence from these various inquiries to show collective impact in our district?" Another facilitator elaborated, "We need to continue to collaboratively reflect on the impact of our regional learning and maintain support in gathering the most effective evidence to demonstrate that learning within our districts."

Second, while all facilitators reported significant increases in their data literacy with respect to classroom evidence-use since the first year of the project, this increase led to deeper questions and more complex challenges for many facilitators by the third year. For example, in year three, facilitators focused on supporting school-based inquiry teams' evidence-use, with an emphasis on helping these educators collect, analyse, and use qualitative classroom data sources to inform teaching and learning in mathematics. In supporting these practices, facilitators recognised the associated need to foster changes in educators' attitudes regarding the value and trustworthiness of qualitative evidence. Likewise, facilitators began to recognise the need for district administrators to appreciate the contribution of qualitative classroom evidence when demonstrating the impacts of professional learning. At the end of the third year, a majority of facilitators expressed a desire to learn more about how: (a) to foster changes in district- and school-level educators' attitudes in relation to qualitative classroom evidence, (b) to facilitate, more effectively, school-based educators' evidence-use in professional learning, and (c) to build 'good evidence' of the systemic impact of professional learning. In summary, one facilitator stated, "It remains a challenge for us. Not all math teachers and administrators understand or 
appreciate qualitative classroom evidence. They want to see numbers and scores to show that this is having an impact, not just descriptions and themes."

In a third but related challenge, nearly all facilitators and teachers collectively recognised that the project's increased focus on qualitative sources of classroom evidence conflicted with provincial report card mandates (these are bi-annual written evaluation reports to parents regarding students' current levels of achievement) and standardised assessment programmes. One teacher explained, "There is a disconnect between how we are learning to teach and assess math in our classrooms and how math achievement is still being reported and measured through standardised assessments. Traditional reporting methods don't fully capture what my students know and can do in math." Throughout the third year of the project, facilitators and teachers increasingly explored tensions between new approaches to classroom assessment and provincial reporting methods and assessment priorities during collaborative learning sessions. Another teacher explained, "Math assessment has become less linear, more fluid, broader. This has opened our eyes to so many more possibilities across the math curriculum. But we need help navigating challenges between these new approaches and traditional report card requirements."

\section{Supports enabling evidence-use}

Facilitators described a number of support strategies that allowed them to build their capacity in data/research literacy and address challenges in evidence-use, specifically: (a) regular crossdistrict collaborative facilitator learning sessions, (b) involvement of pedagogical and research experts, and (c) a "loose-tight" approach to regional collaborative inquiry (i.e., flexibility to adapt professional learning content and processes to their own district's specific needs and goals, 
while maintaining a loose alignment with the project's overarching goals). All facilitators highly valued their regular cross-district sessions with facilitators from other school districts. These meetings created a network of support for facilitators, emphasising professional knowledge regarding frameworks to support collaborative learning and evidence-informed practice within and across regional contexts. All sessions were grounded in relevant educational research evidence and strategically supported by pedagogical and research experts. Moreover, a specific focus throughout these meetings was on how to use classroom evidence to inform and monitor the impact of collaborative inquiry. One facilitator noted, "A key factor for me has been our regular meetings as a region - having a monthly opportunity to work and learn together has supported us going back to our Board's work. It has really created a professional learning community that I can draw on in my work." These collaborative sessions allowed district facilitators to build regional relationships among facilitators, project leads, and affiliated experts and to generate professional knowledge on a regional scale that addressed emerging challenges. As one facilitator commented, "We leave each session with gratitude for having the opportunity to discuss ideas and challenges with others in similar roles. What we gain is a renewed sense of purpose and the motivation to minimise any roadblocks."

The second articulated support was the involvement of pedagogical and research experts, who helped build capacity in research-based practices and inquiry processes, including identifying a precise area of inquiry, engaging in purposeful data collection, analysing data systematically, and using evidence to inform next steps. Facilitators recognised the influence of two kinds of experts: pedagogic (i.e., those who support learning regarding mathematics and instruction), and research (i.e., those who support learning about research evidence). Five districts consistently made use of 
both mathematics and research experts. In these districts, facilitators reported changes in teachers' approaches to mathematics pedagogy and assessment in schools and classrooms, as well as changes in their own use of evidence to inform district- and school-level learning. For example, facilitators in one district reported that teachers began to engage in pedagogical documentation to assess students' mathematical learning, while these facilitators concurrently began to engage in pedagogical documentation of teachers' learning in the project. Accordingly, these facilitators prioritised continued partnerships with mathematics and research experts throughout the project to support implementation and monitoring of mathematics pedagogy and inquiry processes. One facilitator explained that the "experts provided critical opportunities to build my capacity, as well as other educators involved in the project, with respect to math knowledge for teaching, facilitation practices, professional learning frameworks, inquiry processes, and evidence-use."

Lastly, all facilitators articulated that the project's "loose-tight" approach to collaborative inquiry was a critical support for their capacity to use evidence to support teacher professional learning. Within the regional project, facilitators were given the flexibility to adapt professional learning content and processes to their own district's specific needs and goals, while maintaining a loose alignment with the project's overarching goals. The "tight" focus provided a common language and purpose for regional meetings and learning; however, the "loose" nature of the project allowed facilitators across the nine districts to engage in and support inquiries that were meaningful and relevant to their local contexts. These inquiries were aligned with their district and schools' goals, professional learning activities, and data collection priorities. One facilitator elaborated, "Involvement in this project has only reinforced my thinking about the power of 
collaborative inquiry to transform practice. Intentional conversations about assessment and instructional practices and then watching these implemented in classrooms has the power to tumble long held beliefs. Once a misconception is revealed, wonderings and true inquiry begins to grow. Without this inquiry mindset, not much happens or only superficial or incidental learning takes place." A teacher further explained, "Professional learning through collaborative inquiry needs to be relevant at the grassroots level. It can't be prescriptive or rigid. It has to be authentic — it may be big and messy, but it's also meaningful and purposeful!" This quotation highlights the perceived importance, among educators, of utilising local classroom evidence to inform collaborative inquiry-based professional learning.

\section{Changing attitudes about evidence}

Overall, the majority of facilitators and teachers involved in the project readily incorporated the research evidence that was presented by pedagogical experts to inform their initial collaborative inquiry foci. "We have used the math expert to support us in new ways of thinking about math teaching," noted one facilitator. Another teacher stated, "The research gives us things to try to respond to our inquiry focus." Facilitators and teachers both reported using experts and research evidence to formulate and guide their professional learning actions. However, these participants rarely articulated a critical stance towards the research evidence. Coupled with findings demonstrating limited data literacy, there appears to be a gap in educators' capacity to interrogate and evaluate research evidence (i.e., research literacy): rather, they generally accepted the evidence presented by the pedagogic expert without questioning its reliability, empirical basis, or validity. This finding was evident in both facilitator and teacher responses to questions about research evidence-use. One facilitator stated, "I could spend hours online looking for inspiration videos or 
tools, but experts can pinpoint specific research-based resources that will help me support math teaching and learning in my schools." In addition, a teacher commented, "Research experts point us in the direction of the most current and useful research to guide our work. We don't have the time or knowledge to find this research ourselves."

While participants maintained non-critical stances toward research evidence throughout the three years, by the end of the project, the majority of facilitators reported significant shifts in their attitudes about the use of classroom evidence to guide professional learning, which extended to many teacher participants. In year one of the project, facilitators' conceptions of classroom evidence were largely one dimensional — focused on quantifiable surveys and tests (such as fixed-response teacher surveys and graded paper-pencil student products) to inform and demonstrate the impacts on professional learning. As such, their initial attitudes toward classroom and project evidence relied on scientific conceptions of research aimed to implement standardised measures through experimental or quasi-experimental designs. One facilitator stated, "We used to think that evidence had to be in the form of numbers and scores. Now we understand that we can demonstrate teacher and student learning in multiple ways through description as well as scores." Throughout the second and third years of the project, facilitators began to explore and recognise the value of diverse evidence sources that elucidated nuanced impact on teacher and student learning within the project. In particular, facilitators began to recognise the importance of including qualitative classroom data sources along with quantitative data sources. As one facilitator observed, "There has been a real evolution in everyone's approach - not only to the challenges to be overcome, but also in how we can use multiple sources of data to address those challenges." In these ways, facilitators in the project moved 
towards a blended approach that included both quantitative and qualitative data sources.

In a related vein, facilitators indicated that teachers also changed their attitudes with respect to diverse classroom assessments and forms of evidence. As facilitators developed confidence with and appreciation for a blended approach to data collection, they increasingly modelled and supported teachers' use of both quantitative and qualitative data sources. Teachers in both elementary and secondary classrooms began to appreciate the rich information provided by qualitative data and began using these more routinely to support their professional learning and practice. Linked to this change was a realisation of the limits and value of various types of evidence. In particular, participants became increasingly aware that changes in students' learning as a result of professional learning may not be readily apparent in quantitative measures but reflected in qualitative responses. By the end of the third year, facilitators noted changes in teachers' approaches to assessment which had, in the words of one, "positively impacted the cultures and mindsets around data use in both elementary and secondary math classrooms."

Facilitators observed that teachers had developed trusting relationships with students through processes associated with pedagogical documentation and assessment for learning, especially conversations and feedback. Accordingly, teachers began to demonstrate a more asset-minded orientation toward their students, building instruction around students' strengths instead of focusing on gaps in their achievement. As one facilitator explained, "Teachers traditionally saw assessment as the student's ability or inability. Changing the approach to assessment has changed teachers' mindsets toward students in math.” Consequently, students increasingly felt that teachers valued their thinking in mathematics and began to take more risks in their mathematics 
learning. As one facilitator phrased it, "Teachers are able to see/hear/notice where their students are at and are able to meet them where they are. Accordingly, students are participating more during math lessons." A teacher further elaborated, "It isn't just about paper-pencil now. As a result, the students are more engaged in the learning - they enjoy math and they find it fun. And it's fun for us to teach because they're so engaged and their wonderings are coming out." Another teacher reflected, "At the end of the day, I feel that I'm better able to understand each student's ability more and be able to personalise their instruction better the next day." Overall, facilitators' and teachers' broadening conceptions of 'what counts as evidence' in the classroom enriched their learning within the project and enabled more valid representation of the project's impact on mathematics teaching and learning across the region.

\section{Discussion}

Using middle leaders to facilitate system change and teacher professional development has emerged as a leading strategy across many educational systems, with a growing body of associated research (Fullan 2015; Hargreaves and Ainscow 2015; Hattie 2013). In this study, we focused discretely on the role of middle leaders in supporting teachers' evidence-use within the context of networked professional learning in Ontario, Canada. By examining the experiences of 30 middle leaders (i.e., system facilitators) and 54 teachers involved in a three-year collaborative learning project across nine school districts, we were able to identify support strategies and challenges that influenced evidence-use. Findings from this study can suggest specific implications for supporting middle leaders within a collaborative inquiry approach to networked professional learning. 
Within current collaborative inquiry models of professional learning, middle leaders and teachers are commonly required to integrate both research- and classroom-based evidence to respond collectively to identified problems of practice (DeLuca et al. 2015; Donohoo 2013; Nelson and Slavit 2008). In line with previous studies (Campbell and Levin 2009; Earl and Katz 2006; Fullan 2007, 2015), our research suggests that middle leaders and teachers incorporate researchbased evidence to guide their collaborative inquiry focus through the guidance of pedagogical experts. However, due to low levels of research literacy and limited time, participants do not fully interrogate the reliability, empirical-basis, or validity of this evidence. Rather, middle leaders and teachers readily use the evidence provided by experts to shape their inquiry focus and develop new pedagogical strategies. Moreover, participants in our study were unlikely to question the presented evidence or to use additional research evidence to corroborate their own experiences or help analyse their classroom evidence. This suggests that middle leaders and teachers may need intentional support to help them evaluate and use research evidence effectively, throughout the entire collaborative inquiry process (i.e., from formulating inquiry questions to developing and interpreting classroom actions) and in conjunction with classroombased evidence.

A notable finding from our data was that middle leaders and teachers were able to change their attitudes to classroom evidence in order to support and justify their professional learning. While participants initially lacked the data literacy to make effective use of classroom evidence to support their professional inquires, these participants were able to cultivate broader understandings about inquiry processes and classroom evidence through targeted support from research experts. First, participants reconceptualised the role of evidence within the context of 
their professional learning. Middle leaders and teachers in this study quickly realised that evidence-based professional learning not only requires the use of proven pedagogical strategies but, perhaps more importantly, requires educators to generate and analyse evidence in order to reflect on and refine their instructional approach. Second, participants in this study had to change their attitudes about sources of valid and useful evidence to guide professional learning. Many middle leaders and teachers initially held traditional assumptions about research and evidence, favouring experimental and quasi-experimental designs reliant on standardised measures. By the end of the project, both middle leaders and teachers had adopted a more balanced approach to integrating diverse quantitative and qualitative sources of evidence to demonstrate impact at classroom, school, and district levels, and were beginning to reflect a networked learning system committed to assessment for learning strategies (Campbell and Levin 2009; Earl and Katz 2006).

Underpinning effective classroom evidence-use is educators' data literacy - their capacity to collect, analyse, and use multiple sources of classroom and external data to inform and monitor professional learning. Our findings highlight that, without sufficient data literacy, educators tend to rely on one-dimensional measures (such as graded classroom assessments, standardised assessments, or fixed-response surveys) that do not enable fully valid conclusions about intended professional learning outcomes. This study also indicates that educators rarely interrogate or evaluate research evidence before incorporating it into their collaborative inquiry. This potentially leads to inquiry being informed by research evidence that is lacking in trustworthiness. Future research should heed the importance of educators' capacity for both data and research literacy. 
While this study begins to address a gap in research pertaining to the role of middle leaders in supporting teachers' evidence-use within educator professional learning, we acknowledge three limitations of our work. First, this research targets a regional professionals' learning initiative in one Canadian province, inevitably limiting the transferability of findings to other systems or settings. Second, the focus of this professional learning was mathematics - it cannot be assumed that middle leaders' support of evidence-use among teachers in a different subject area would necessarily align with our findings. Finally, as mentioned earlier in the paper, our study included focus group data from a small proportion of already motivated teachers involved in the regional project. Additional teacher data, including observations and artefacts, as well as a wider range of teachers with lower levels of pre-disposition towards engagement with evidence, would serve to explore further the teacher's role and experience of evidence-use, which fell beyond the scope of our study.

Despite these limitations, we believe that the present study contributes to the literature by offering findings that support middle leader practice and inform future research in systemic evidence-use and teacher education. Specifically, we see value in pursuing research that empirically examines: (a) diverse strategies to support middle leaders' integration and use of research- and classroom-based evidence throughout the entire collaborative inquiry cycle and in relation to classroom, school, district, and regional impacts; (b) structures that enhance both data and research literacy of middle leaders and teachers through diverse professional learning models; and (c) the effective role of middle leaders in promoting evidence-use across other collaborative professional learning contexts (i.e., diverse regions and subjects). Overall, this research agenda will contribute to systemic capacity building for greater evidence-use by middle 
leaders and teachers, ultimately supporting a change in attitudes and practices in relation to evidence-informed teaching and learning at classroom, school, and district levels. 


\section{References}

Avalos, B. 2011. "Teacher Professional Development in Teaching and Teacher Education over Ten Years.” Teaching and Teacher Education, 27: 10-20. doi: 10.1016/j.tate.2010.08.007.

Bore, A., and N. Wright. 2009. "The Wicked and Complex in Education: Developing a Transdisciplinary Perspective for Policy Formulation, Implementation and Professional Practice." Journal of Education for Teaching, 35 (3): 241-256. doi: $10.1080 / 02607470903091286$.

Borko, H. 2004. "Professional Development and Teacher Learning: Mapping the Terrain." Educational Researcher, 33: 3-15. doi: 10.3102/0013189X033008003.

Campbell, C., and B. Levin. 2009. "Using Data to Support Educational Improvement." Educational Assessment, Evaluation and Accountability, 21 (1): 47-65. doi: 10.1007/s11092-008-9063-X.

Chappuis, S., J. Chappuis, and R. Stiggins. 2009. "Supporting Teacher Learning Teams." Educational Leadership, 66 (5): 56-60. url: http://www.ascd.org/publications/educationalleadership/feb09/vol66/num05/Supporting-Teacher-Learning-Teams.aspx.

Cochran-Smith, M., and S. L. Lytle. 2009. Inquiry as Stance: Practitioner Research for the Next Generation. New York, NY: Teachers College Press.

Cooper, A., B. Levin, and C. Campbell. 2009. “The Growing (but still limited) Importance of Evidence in Education Policy and Practice.” Journal of Educational Change, 10: 159-171. doi: 10.1007/s10833-009-9107-0.

Darling-Hammond, L. 2010. "Teacher Education and the American Future." Journal of Teacher Education, 61 (1-2): 35-47. doi: 10.1177/0022487109348024. 
Darling-Hammond, L., and N. Richardson. 2009. "Research Review/Teacher Learning: What Matters.” Educational Leadership, 66 (5): 46-53. url: http://www.ascd.org/publications/educational-leadership/feb09/vol66/num05/TeacherLearning@-What-Mattersф.aspx.

Davis, B., and D. J. Sumara. 2006. Complexity and Education: Inquiries into Learning, Teaching, and Research. New York, NY: Routledge.

DeLuca, C., J. Shulha, U. Luhanga, L. M. Shulha, D. A. Klinger, and T. Christou. 2015. “Collaborative Inquiry as a Professional Learning Structure for Educators: A Scoping Review." Professional Development in Education, 41 (1): 640-670. doi: 10.1080/19415257.2014.933120.

Desimone, L. 2009. “Improving Impact Studies of Teachers’ Professional Development: Toward Better Conceptualizations and Measures.” Educational Researcher, 38 (3): 181-199. doi: 10.3102/0013189X08331140.

Donohoo, J. 2013. Collaborative Inquiry for Educators: A Facilitator's Guide to School Improvement. Thousand Oaks, CA: Corwin.

Earl, L., and S. Katz. 2006. Leading in a Data Rich World: Harnessing Data for School Improvement. Thousand Oaks, CA: Corwin.

Elmore, R. F. 2004. School Reform from the Inside Out: Policy, Practice, and Performance. Cambridge, MA: Harvard Education Press.

Ermeling, B. A. 2010. “Tracing the Effects of Teacher Inquiry on Classroom Practice.” Teaching and Teacher Education: An International Journal of Research and Studies, 26 (3): 377388. doi: 10.1016/j.tate.2009.02.019.

Fullan, M. 2007. The New Meaning of Educational Change. New York, NY: Routledge. 
Fullan, M. 2009. "Large-scale Reform Comes of Age.” Journal of Educational Change, 10 (2-3): 101-113. doi: 10.1007/s10833-009-9108-z.

Fullan, M. 2015. "Leadership from the Middle: A System Strategy.” Education Canada 56 (3): 22-26. url: http://www.cea-ace.ca/education-canada/article/leadership-middle.

Fullan, M., and J. Knight. 2011. “Coaches as System Leaders.” Educational Leadership, 69 (2): 50-53. doi: http://www.ascd.org/publications/educationalleadership/oct11/vol69/num02/Coaches-as-System-Leaders.aspx,

Guskey, T. 2014. "Measuring the Effectiveness of Educators' Professional Development.” In Handbook of Professional Development in Education, edited by L. E. Martin, S. Kragler, D. J. Quatroche, \& K. L. Bauserman, 447-466. New York, NY: Guilford Press.

Guskey, T., and K. Yoon. 2009. "What Works in Professional Development." Phi Delta Kappan, 90: 495-500. url: http://www.keystoliteracy.com/wp-content/pdfs/orc-implementscience/What\%20works\%20in\%20PD.pdf.

Hargreaves, A., and M. Ainscow. 2015. "The Top and Bottom of Leadership and Change." Phi Delta Kappan, 97 (3): 42-48. doi: 10.1177/0031721715614828.

Hattie, J. 2013. Visible Learning: A Synthesis of Over 800 Meta-analyses Relating to Achievement. New York, NY: Routledge.

Huffman, D., and J. Kalnin. 2003. "Collaborative Inquiry to Make Data-based Decisions in Schools." Teaching and Teacher Education, 19 (6): 569-580. doi: 10.1016/S0742051X(03)00054-4.

Katz, S., and L. Earl. 2010. "Learning About Networked Learning Communities.” School Effectiveness and School Improvement, 21 (1): 27-51. doi: 10.1080/09243450903569718.

Kennedy, A., A. Deuel, T. H. Nelson, and D. Slavit. 2011. "Requiring Collaboration or 
Distributing Leadership?". Phi Delta Kappan, 92 (8): 20-24. url: http://mcpsonline.org/images/8/88/21CC2011_Requiring_Collaboration.pdf.

Killion, J. 2012. "Coaching in the K-12 Context." In The Sage Handbook of Mentoring and Coaching in Education, edited by S. J. Fletcher \& C. A. Mullen, 273-294. Los Angeles, CA: Sage.

Leithwood, K., R. Aitken, and D. Jantzi. 2006. Making Schools Smarter: Leading with Evidence. Thousand Oaks, CA: Corwin Press.

Moolenaar, N. M. 2012. “A Social Network Perspective on Teacher Collaboration in Schools: Theory, Methodology, and Applications." American Journal of Education, 119 (1): 7-39. doi: $10.1086 / 667715$.

Muijs, D., M. West, and M. Ainscow. 2010. "Why Network? Theoretical Perspectives on Networking." School Effectiveness and School Improvement, 21 (1): 5-26. doi: 10.1080/09243450903569692.

Namey, E., G. Guest, L. Thairu, and L. Johnson. 2008. "Data Reduction Techniques for Large Qualitative Data Sets." In Handbook for Team-based Qualitative Research, edited by G. Guest and K. M. MacQueen, 137-161. Lanham, MD: AltaMira Press.

Nelson, T. H., and D. Slavit. 2008. "Supported Teacher Collaborative Inquiry." Teacher Education Quarterly, 35: 99-116. url: http://files.eric.ed.gov/fulltext/EJ810660.pdf.

Opfer, V., and D. Pedder. 2011. "Conceptualizing Teacher Professional Learning." Review of Educational Research, 81 (3): 376-407. doi: 10.3102/0034654311413609.

Patton, M. Q. 2002. Qualitative Research and Evaluation Methods (3rd ed). Thousand Oaks, CA: Sage. 
Quatroche, D. J., K. L. Bauserman, and L. Nellis. 2014. “Supporting Professional Growth through External Resources." In Handbook of Professional Development in Education, edited by L. E. Martin, S. Kragler, D. J. Quatroche, and K. L. Bauserman, 431-442. New York, NY: Guilford Press.

Robinson, M.A. 2010. “School Perspectives on Collaborative Inquiry: Lessons learned from NewYork City, 2009-2010.” Philadelphia, PA: Consortium for Policy Research in Education.

Schildkamp, K., C. L. Poortman, and A. Handelzalts. 2016. "Data Teams for School Improvement.” School Effectiveness and School Improvement, 27 (2): 228-254. doi: 10.1080/09243453.2015.1056192.

Sin, C. H. 2008. "The Role of Intermediaries in Getting Evidence into Policy and Practice: Some Useful Lessons from Examining Consultancy-Client Relationships.” Evidence \& Policy, 4 (1): 85-103. doi: 10.1332/174426408783477828.

Timperley, H. 2011. Realizing the Power of Professional Learning. New York, NY: McGrawHill.

Vineyard, L. 2010. Collaborative Inquiry: A Strategy for Assessing Response to Instruction and Intervention (RtI ${ }^{2}$ for English Learner Students. (Doctoral dissertation). Available from ProQuest Dissertations \& Theses database. (UMI No. 3446801)

Wellman, B., and L. Lipton. 2004. Data-driven Dialogue: A Facilitator's Guide to Collaborative Inquiry. Mira Via, LLC. 